\title{
Effects of finishing boars in mixed and single sex groups and split marketing on pig welfare L Björklund ${ }^{* 1}$ and LA Boyle ${ }^{2}$
}

\begin{abstract}
Address: ${ }^{1}$ Linköping University, Linköping, Sweden and ${ }^{2}$ Livestock Production Centre, Moorepark, Fermoy, Co Cork, Ireland
\end{abstract}
* Corresponding author

from Prevention of Boar Taint in Pig Production: The 19th Symposium of the Nordic Committee for Veterinary Scientific Cooperation Gardermoen, Norway. 2 I-22 November 2005

Published: 7 August 2006

Acta Veterinaria Scandinavica 2006, 48(Suppl I):P2 doi:I0.II86/I75I-0I47-48-SI-P2

(C) 2006 Björklund and Boyle.; licensee BioMed Central Ltd.

\section{Introduction}

In Ireland, pigs were traditionally slaughtered at low weights and hence at a young age, which facilitated the rearing of boars. However, slaughter weights are increasing and this is associated with an increased risk of boar taint [1] and welfare problems [2]. Hence, changes in management and housing practices to facilitate rearing of heavy boars need to be investigated. The aims of this study were to investigate the welfare of pigs of both sexes in single or mixed sex groups and to evaluate effects of split marketing on pig welfare.

\section{Materials and Methods}

Pigs were assigned to female $(\mathrm{n}=10)$, male $(\mathrm{n}=10)$ and mixed $(n=10)$ sex treatment groups (14 pigs/pen) at transfer from the weaner accommodation (c. $35 \mathrm{~kg}$ ). Once the mean weight of the pen reached $70 \mathrm{~kg}$ the group size was reduced to 12. Data collection began when the mean weight of the pen reached $75 \mathrm{~kg}$. Once the average weight of the pen was $100 \mathrm{~kg}$, the three heaviest pigs from five of the groups in each treatment were sent for slaughter (i.e. split-marketed). The remaining pigs were slaughtered the following week (c. $105 \mathrm{~kg}$ ). Two focal animals/pen were inspected for skin lesions at 75, 90, 100 (prior to split marketing) and $105 \mathrm{~kg}$. Twelve regions on the body were scored from 0 to 5 depending on the number and depth of the lesions in each location. The total score for each pig was the sum of the scores for the 12 areas. Behaviour observations were conducted at 75, 95 and 100 (post split marketing) kg. The behaviour of each focal animal was recorded continuously for 10 minutes on three days per week between 1030 and $1300 \mathrm{~h}$ and 1500 and $1800 \mathrm{~h}(60$ minutes/pig). Recordings were made by direct observa- tion using The Observer program downloaded to a Psion organiser. All occurrence behaviour sampling was also used to record the frequency of agonistic (threats, knocks, bites, fights) and sexual (mounts and nudges) behaviours during feeding. Observations started ten minutes before feeding and finished 20 minutes later. Each pen was observed for 1.5 minutes at each of six feeding events, three at 0900 and $1400 \mathrm{~h}$ yielding nine minutes/pen.

All data were analysed by SAS. Data on skin lesion scores collected at the 75, 90 and $100 \mathrm{~kg}$ inspections were analysed by a mixed model. Skin lesion data collected at the $105 \mathrm{~kg}$ inspection were analysed by analysis of variance using the general linear model procedure. Behaviour data were non-parametric and were analysed by the KruskalWallis test.

\section{Results}

There was no effect of treatment on skin lesion scores at 75,90 or $100 \mathrm{~kg}(P>0.05)$. However, there was a significant interaction between treatment and split marketing on skin lesion scores at $105 \mathrm{~kg}(\mathrm{P}<0.05)$. Pigs in splitmarketed male groups tended to have higher scores than pigs in male groups that were not split-marketed (24.6 vs. 18.1 SEM 1.65, $\mathrm{P}<0.10)$.

There was more mounting in male and mixed compared to female groups at all weights $(\mathrm{P}<0.05)$. However, the frequency of mounting in mixed groups decreased over time $(\mathrm{P}<0.01)$. Split marketing reduced the number of mounts in the mixed groups to a level comparable to that recorded both in female groups that were split marketed and in those that were not $(\mathrm{P}<0.05$, Figure 1$)$. 


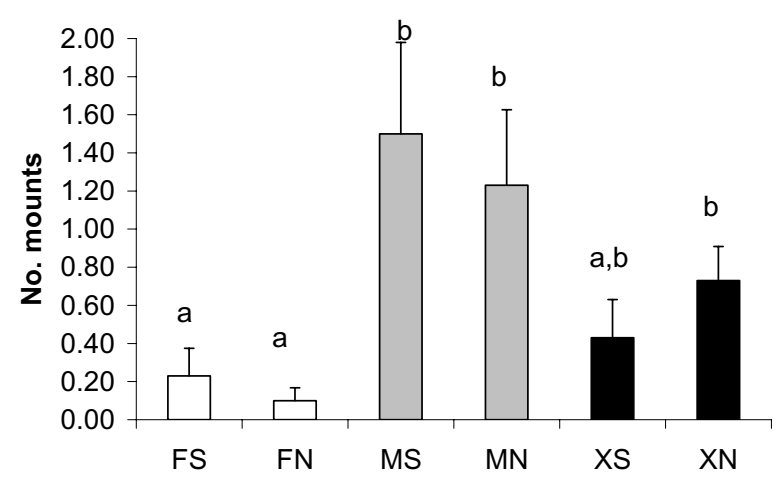

Figure I

Effect of split marketing on the frequency of mounts (mean + s.e.) observed in female $(F)$, male $(M)$ and mixed $(X)$ sex groups (ab $\mathrm{P}<0.05, \mathrm{~S}=$ split marketed, $\mathrm{N}=$ not split marketed).

There was more agonistic behaviour in male $(14.5 \pm 1.10)$ compared to female $(10.3 \pm 1.15)$ and mixed sex $(10.5 \pm$ 1.34) groups during feeding $(\mathrm{P}<0.05)$. Split marketing had no effect on agonistic behaviour $(\mathrm{P}>0.05)$.

\section{Discussion}

Mounting is a normal part of the sexual behavioural repertoire of males in most farm animal species [3]. Not surprisingly then, and in accordance with Rydhmer et al. [2], the frequency of this behaviour was higher in male and mixed groups than in female groups. Sexual behaviour has adverse welfare implications [2] particularly for pigs housed in confined spaces on slatted floors. Hence, the welfare of females in single sex groups was improved relative to that of females in mixed sex groups.

On the other hand, male pigs were exposed to higher levels of agonistic behaviour in single compared to mixed sex groups at feeding. Furthermore, there was a reduction in mounting behaviour in the mixed groups over time but the same effect was not observed in the male groups. These findings suggest that the welfare of the male pigs was improved in the mixed compared to the single sex groups.

Split marketing resulted in a reduction in mounting behaviour in the mixed groups. Generally the heaviest pigs in mixed groups were male, so split marketing resulted in three males being removed from the group. These animals were likely to have been responsible for most of the mounting. In contrast, split marketing caused an increase in skin lesion scores of pigs in male groups suggesting that the practice had negative welfare implications in such groups. The removal of individuals from a group causes some disruption to the dominance hierarchy that can stimulate aggression [4]. It is likely that this effect is aggravated in groups of boars compared to groups of females, the former being naturally more aggressive.

In conclusion, rearing females in single sex groups eliminates any potential welfare problems for these animals of rearing boars. On the contrary, boars themselves are exposed to more aggression if finished in single rather than mixed sex groups. Single sex rearing of boars in conjunction with split marketing further aggravates the problem. Single sex rearing combined with slaughtering boars earlier than their female counterparts might reduce the need for split marketing and ameliorate some welfare problems.

\section{References}

I. Dunshea RF, et al:: Vaccination of boars with a GnRH vaccine (Improvac) eliminates boar taint and increases growth performance. Journal of Animal Science 200I, 79:2535-2535.

2. Rydhmer L, et al.: Problems with aggressive and sexual behaviour when rearing entire males. In the Proceedings of the 55th Annual meeting of the European Assoc. for Animal Production (EAAP) Bled, Slovenia; 2004

3. Fraser, Broom : Farm animal behaviour and welfare 3rd edition. $C A B$ INTERNATIONAL, Wallingford, UK; 1997.

4. Gonyou HW: The social behaviour of pigs. In Social behaviour in farm animals Edited by: Keeling LJ, Gonyou HW. CABI Publishing, Wallingford, UK:147-167.

\section{Publish with Biomed Central and every scientist can read your work free of charge}

"BioMed Central will be the most significant development for disseminating the results of biomedical research in our lifetime. " Sir Paul Nurse, Cancer Research UK

Your research papers will be:

- available free of charge to the entire biomedical community

- peer reviewed and published immediately upon acceptance

- cited in PubMed and archived on PubMed Central

- yours - you keep the copyright

Submit your manuscript here:

http://www.biomedcentral.com/info/publishing_adv.asp 